\title{
obituary
}

\section{A. R. Luria}

Alexander Romanovitch LuRia, the distinguished Soviet neuropsychologist, died in Moscow on 14 August, 1977, at the age of 75 .

He was born in 1902 and educated at the Universities of Kazan and Moscow, where he took his degree in psychology, later qualifying also in medicine. A talented experimental psychologist, his best known work was concerned with the analysis of psychological disabilities resulting from war wounds of the brain. But his interests covered a wide range of themes in experimental psychology, in particular problems of language and its acquisition in young children. He paid several visits to this country and a number of his books have been translated into English.

Luria's earliest work was concerned with the analysis of motor disorganisation provoked by conflict and stress. This was based on a long series of experimental studies carried out at the State Institute of Experimental Psychology in Moscow in the 'twenties and published as a book which appeared in English translation in 1932. Although deriving in some measure from Jung and Peterson's work on word-association and the psychogalvanic response, Luria was concerned with the disruption of volitional movement rather than with autonomic changes and did much to extend the use of objective method in the study of emotional stress.

Rather surprisingly, his work owed but little to Pavlov, who at much the same time was investigating experimental neuroses in dogs by conditioned reflex techniques. While Luria held Pavlov's physiological work in the highest esteem, relations between physiology and psychology in the Soviet Union have never been close and few Soviet psychologists espoused behaviourism. As with the great majority of Soviet psychologists, Luria's outlook was far from Pavlovian and his work was wholly confined to the study of human experience and behaviour.

The most important figure in Russian psychology after the Revolution was L. S. Vygotsky, Luria's predecessor in the Chair of Psychology in the University of Moscow and a man. who influenced him greatly. Vygotsky's main interests lay in child development, more especially in the study of

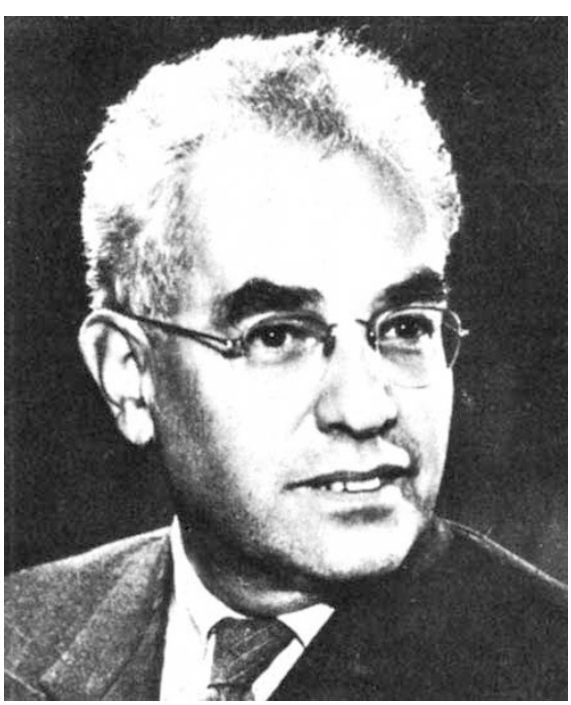

language and its relation to intellectual growth. Following Pavlov's suggestion that the main differences between human and animal behaviour are bound up with the evolution of language, Luria concerned himself particularly with the acquisition of language in young children and its effects on the learning of motor skills.

Although relatively little of this work was translated, he brought much of it together in a series of three lectures delivered at University College London in 1958 and subsequently published as a short book under the title of Speech and the Regulation of Normal and Abnormal Behaviour (1961). More physiological in tone than Vygotsky, Luria followed him in his full acceptance of the importance of language in the intellectual development of the child. In this respect he stands far closer to Piaget than to Pavlov.

Interested as he was in the acquisition of language, Luria was even more concerned with the nature of its dissolution. His studies of aphasia, somewhat in the tradition of Hughlings Jackson and Henry Head, remain perhaps as his outstanding contribution to neuropsychology. During the last war, Luria was closely concerned with the assessment of psychological disability in brain-injured servicemen and in formulating programmes of rehabilitation based upon thorough psychological examination. His book on Traumatic Aphasia (1947, English translation 1970), is especially noteworthy for its detailed analysis of the various patterns of linguistic disability resulting from brain injury and their relationship to the site and extent of the cerebral lesion.

Some years later, his considered views on the problems of cerebral localisation together with an exposition of his methods for eliciting specific psychological deficits were set out in a noteworthy monograph. This was Higher Cortical Functions in Man (1963, English translation 1966), which has had wide influence. Although putting forward no new theory or model of higher nervous activity, the subtlety and intuitive skill displayed by Luria in devising simple methods for analysing cortical defects and evaluating their significance represents a major achievement.

Apart from his scientific preoccupations, Luria was a man with lively human sympathies who achieved an unusual degree of empathy with the victims of brain injury. Among these was the distinguished physicist, L. D. Landau, to whose rehabilitation after a severe head injury Luria devoted quite outstanding skill and care. Nor were his ministrations limited to the famous, as is witnessed by his moving account of the visual and symbolic difficulties of a completely unknown young scientist who had sustained a penetrating occipitoparietal war wound of the dominant cerebral hemisphere. This case is described in The Man with a Shattered World (1972), a semipopular book written with unusual sensitivity and very considerable literary skill. As has been well said elsewhere, Luria was a very warm human being and a deeply compassionate and concerned physician with something of the artist in his composition.

Alexander Luria was a holder of the Order of Lenin and received many other honours from his own country and further afield. He was a foreign member of the National Academy of Sciences of the United States and an Honorary Fellow of the British Psychological Society. He was awarded an Honorary Doctorate of Science by the University of Leicester. $\mathrm{He}$ is survived by his widow, herself a medical scientist, and daughter.

O. L. Zangwill

\section{Jean Maetz}

JEAN MAETz died tragically in a road accident in Scotland on 16 August, 1977. He was Chief of the Groupe de Biologie Marine of the Département de 
Biologie du Commissariat à L'Energie Atomique located at the Station Zoologique, Villefranche-sur-Mer, France. Born in Mutzig in Alsace in 1922, he was educated at the Ecole Normale Supérieure in Paris, and worked at Saclay before going to Villefranche in 1964.

Early attempts to measure teleostean osmoregulation with radioisotopes had been made in the fifties, and revived by Motais in 1961. Maetz with Motais in 1965 discovered that in sea-water the gill was the major site of sodium exchange, and that up to $100 \%$ of the internal sodium could be exchanged each hour. Maetz was quick to realise the importance of techniques which allowed both influx and efflux of ions across the gill to be measured while the salt balance of the animal was not disturbed. He refined and automated these techniques with the effect that a constant stream of papers has flowed from his laboratory in which a variety of perturbations (ionic strength, temperature, hormones) were employed and their effects on branchial fluxes described. He was particularly interested in problems of adaptation in euryhaline fishes and while he stressed the difficulty of obtaining exact thermodynamic data in whole animals he enjoyed building models to describe the data. These wore intended as a challenge to others to do experiments designed to test the models.

It is in no small part due to his stimulus that there is a lively interest in branchial transport today. While there is now general agreement about the active transport of chloride in the seawater gill, the mechanism of $\mathrm{Na}-\mathrm{K}$ exchange is more controversial. Whether exchange proceeds by an active mechanism or is a result of potential changes accompanying alterations in composition of external medium is still a matter of dispute. Although Maetz with Campanini in 1966 were the first to show the change in gill potential which followed when eels were transferred from sea water to fresh water Maetz initially favoured an active mechanism. More recent observations suggest that $\mathrm{Na} / \mathrm{K}$ exchanges are diffusive in nature, yet awkward observations remain to indicate that some component of the exchange is potential insensitive. It is a tragedy he will not be able to resolve this matter after contributing so much of the information on which the discussion is based.

The impact of the mass of phenomenological data, collected for many diflerent species, which has come from his efforts has perhaps not yet been realised. Its importance to ecology and relevance with regard to the changing environment of the seas and estuaries may be considerable.
More recently he turned to simpler systems such as the perfused gill, work already started with Rankin, and to biochemical and morphological studies of chloride cells. It is to be hoped others will continue to explore his ideas in these areas.

Jean Maetz was a man of great charm with an infectious enthusiasm for research. Many of his former students now hold positions in research institutions and his laboratory was never without visiting scientists, who came from all over the world. A visit to his laboratory was a commitment to do experiments, and often at the end of the day to enjoy the hospitality and friendship offered by his whole family. $\mathrm{He}$ is survived by his wife, Betty, and two daughters.

A. W. Cuthbert

\section{Louis Fieser}

Louis Frederick Fieser was an exemplar of excellence promoted and sustained by Harvard University. Born in Columbus, Ohio, on April 7, 1899, he completed his Ph.D. degree under J. B. Conant at Harvard in 1924. After five years on the staff of Bryn Mawr College (where he discovered his aptitude for teaching) he returned to the Harvard chemistry department in 1930 , becoming Sheldon Emery Professor of Organic Chemistry (1939-1968) and Professor Emeritus from 1968 until his death on July 25, 1977.

Among the honours conferred on Fieser were Fellowship of the National Academy of Sciences (1940), and the D.Pharm. honoris causa of the University of Paris (1953). From the American Chemical Society he received the Wm. H. Nichols Medal (1963) and the Award in Chemical Education (1967).

Fieser's abounding enthusiasm for investigative organic chemistry was rooted in his own experimental work, which he continued throughout his career. His attachment to bench work is well portrayed in the photograph that accompanied a biographical sketch by Dr Hans Heymann in the Journal of Organic Chemistry of June 1965-an issue composed of numerous papers dedicated to Fieser on the occasion of his 66th birthday, by authors from many countries who had been students or post-doctoral workers in the Converse Memorial Laboratory.

Early research by Fieser stimulated developments in several fields which have remained important. In 1939, he established the structure of Vitamin $\mathrm{K}_{1}$ by a synthesis of characteristic practicality, isolating the natural vitamin from alfalfa extract for comparison. Fieser had earlier devised syntheses of methylcholanthrene and other carcinogenic hydrocarbons, and his varied interests led him to compile (with Mary
Fieser) his books on Natural Products Related To Phenanthrene (1936, 1937) in which the developing (and confused) chemistry of the steroids was skilfully elucidated and critically reviewed. In the 1937 volume, Fieser introduced the $\alpha / \beta$ nomenclature now universally employed to designate hydroxy and other substituent configurations in the steroid nucleus. The 3 rd edition appeared in 1949 , benefiting from (and contributing to) the burgeoning of steroid research that accompanied the discovery of the therapeutic value of cortisone.

The ensuing decade saw remarkable advances in steroid chemistry and biochemistry which had an impact in much wider fields. Observations by Fieser on the stereochemistry of steroid reactions were among the stimuli that led D. H. R. Barton (while a Visiting Lecturer at Harvard) to develop the principles of conformational analysis. In addition to participating in many aspects of research on steroids, Fieser found time to compile-again with his wife as co-author --the masterly 4 th edition of the original book, necessarily retitled Steroids (1959) because the wealth of new information compelled the exclusion of other material.

Fieser's insight in selecting significant research topics is exemplified by his early work on benzo $[\alpha]$ pyrene, the carcinogenic action of which has only recently been clarified in structural terms. Another of his interests concerned the possibility that carcinogenicity might arise from minor sterols occurring as companions of cholesterol: he isolated a number of such minor components from commercial cholesterol. Although no carcinogenic sterols (with the exception of cholesterol $\alpha$-oxide) appear to be known, recent work has indicated that certain compounds such as 25-hydroxycholesterol may have significant biochemical effects.

Fieser himself considered that success in teaching was his major accomplishment. At Harvard, his attractive informality as a lecturer won him the students' acceptance of a rigorous introductory course in organic chemistry, generally regarded as 'tough. hut well worth it' by the participantswho numbered more than 8,000 during the 30 years of the course. Experimental skill was assiduously inculcated, as in the annual Martius Yellow prize competition for the practical class, in which 'Louie' frequently took part.

Fieser's earliest texthook, Experiments in Organic Chemistry (1935), and its painstakingly revised successors, conveyed up-to-date techniques to students world-wide: the colour pictures showing how to construct a hot-plate from a can labelled 'Gorton's Cod Cakes' impressed even those readers 